\title{
Intracranial Meningioma Aggressivity Image and Level of Malignancy in Head Magnetic Resonance Imaging (MRI)
}

\author{
Vony Tjandra ${ }^{1}$, Sri Andreani Utomo ${ }^{2}$, Ulinta Purwanti ${ }^{3}$, Dyah Fauziah ${ }^{4}$, Hari Basuki $^{5}$ \\ ${ }^{1}$ Department of Radiology, Faculty of Medicine - Dr.Soetomo General Hospital, Universitas Airlangga, Surabaya \\ 60285, Indonesia, ${ }^{2}$ Neuroradiology Division, Department of Radiology, ${ }^{3}$ Department of Radiotherapy, ${ }^{4}$ Department \\ of Anatomical Pathology, Faculty of Medicine, Universitas Airlangga-Dr.Soetomo General Hospital, Surabaya, \\ ${ }^{5}$ Department of Biostatistics and Population, Faculty of Public Health, Universitas Airlangga
}

\begin{abstract}
Background: Meningioma is the second most common central nervous system neoplasm in adults, usually benign that originally from arachnoid cap cells. Meningioma is categorized by WHO classification as benign (grade I), atypical (grade II), and anaplastic (grade III). Objectives: This study to know strong correlation between the image of intracranial meningioma aggressiveness and malignancy. Method: Restrivectively, forty-intracranial meningiomas of new cases who had undergone surgery from January 2014 to June 2015, preoperative MRI head examination and Anatomy Pathology at Dr. Soetomo Surabaya, observed signs of aggressiveness of meningioma and malignancy rate that analyzed by contingency coefficient and Spearman correlation coefficient. Results: Based on age $30-65$ years; $82.5 \%$ of women and $17.5 \%$ of men was got a strong correlation between bone destruction $(\mathrm{C}=0.533)$; weak association of intratumoral cystic changes $(\mathrm{C}$ $=0.230)$, hyperostosis $(C=0.327)$, vascular encasement $(C=0.327)$; a very weak correlation of extracranial tumor extension $(\mathrm{C}=0.139)$, cerebral peritoneal edema $(\mathrm{C}=0.104)$; with a malignant degree in meningioma. Conclusion: There was a strong correlation between bone destruction and malignancy rates in meningioma.
\end{abstract}

Keywords: Intracranial meningioma, malignancy, MRI, nervous system

\section{Introduction}

Meningiomas are the second most common central nervous neoplasm in adults and most are usually benign, while, slow-growing tumors derived from arachnoid cap cells. Atypical and malignant meningiomas are more common in men. They are rarely present in patients under 40 years old and increase in suspicion of type 2 neurofibromatosis (NF2) in young adults 1-3. NF2 tumor suppressor genes have been found to mutate in large portions of meningioma 4.

The incidence of meningioma every year was 2.3 for each 100,000 , increased by age, and peak in the 7th decade ${ }^{5}$. In the United States from 2002 to 2006 the meningioma frequency reached $33.8 \%$ of all primary tumors in the brain and central nervous system ${ }^{6}$. Two

\section{Corresponding author:}

Sri Andreani Utomo

E-mail: sriandreaniutomo48@yahoo.com studies indicated that the incidence of meningioma in Asian races was lower than in European, however other study reported there was no significant incidence of racebased incidence, with $20.8 \%, 18.5 \%$, and China $16.6 \%{ }^{7}$.

There are many subtypes of histologic meningiomas differin levels ofmalignantbehavior. The most commonly used that WHO classifies are three classes, which have different prognostic properties ${ }^{8}$. Meningiomas were categorized by WHO classification as benign (grade I), atypical (grade II), and anaplastic (grade III), 80\%, 15 $20 \%$, and $1-3 \%$ of all meningioma ${ }^{5}$. respectively. Grade I tumors that do not meet the criteria for higher grade lesions, grade II tumors with increased mitotic activity ( $\geq 4$ mitosis per high power field), Grade III tumors with $\geq 20$ mitosis for each high power field and/or malignant characteristics that resembling carcinomas and sarcoma 9,10 .

Previous studies reported that retrospective studies in 75 patients undergoing intracranial meningioma resection were performed to determine the correlation 
between aggressive imaging features and histopathologic classes in meningioma ${ }^{11}$. Six aggressive imaging were evaluated: intratumoral cystic changes, adjacent cranial hyperostosis, bone destruction, extracranial tumor extension through skull base foramina, vascular encasement and peritumoral cerebral edema. Fiftynine tumors were classified as benign, according to WHO classification and 16 as atypical/malignant. Only intratumoral cystic changes and extracranial tumor extension through the skull base foramina are more prevalent in atypical/malignant meningiomas ${ }^{11,12}$.

Most meningiomas have a good prognosis, frequent surgery, and curative adjuvant radiotherapy. Although, total resection is not always possible because meningiomas might enclose vascular and neural structures, and radiation therapy is limited by neurotoxicity and tumor size. Until now, chemotherapy regimens have minimal effectiveness in the treatment of meningioma ${ }^{12}$. The prognosis worsens with worse differentiation of the tumor ${ }^{13,14}$. MRI can be used as classification process according to type of brain disease such as Glioma, Alzheimer's, and Carcinoma ${ }^{15}$.In cases with intracranial pathology, MRI is an examination option for diagnosis and characteristic of meningioma. When the picture and location are typical, the diagnosis is made to a higher degree 14. Advances in identifying alternative forms of therapy for these patients have been limited by poor understanding of the molecular pathogenesis of meningiomas and molecular critical changes encouraging tumor growth, and by the lack of meningioma cell lines and tumor models for preclinical studies ${ }^{16}$. Therefore, this study aims to look at the picture of intracranial meningioma aggressiveness in head MRI with malignancy rate.

\section{Method}

The cross-sectional study was used with the samples all patients of intracranial meningioma of new cases that have been operated and performed MRI preoperative head examination and Anatomy Pathology in Dr. Soetomo General Hospital Surabaya from January 2014 to June
2015. Data were taken from head MRI examination data that using GE Optima 3601.5 Tesla engine and Anatomy Pathology examination data (MIRSA) from patients with intracranial meningioma of new cases that have been operated in Dr. Soetomo General Hospital Surabaya. The head MRI examination was re-read by 2 neuroradiologists using the Osirinx system to saw signs of aggressiveness of meningioma and then associated with the results of Anatomical Pathology. Data from MRI preoperative head examination and Anatomy Pathology examination result (MIRSA) were collected for observation, and data were analyzed with contingency coefficient and Spearman correlation coefficient using SPSS 21 (SPSS, Inc., Chicago, IL.).

\section{Results}

The sample was 40 people, drawn from the total sample size of patients diagnosed with intracranial meningioma of newly operated cases and performed preoperative head MRI examination also anatomical pathology examination at Dr. Soetomo General Hospital Surabaya.

\section{Frequency of Malignancy Rate}

Table 1. Frequency of meningioma malignancy

\begin{tabular}{|l|l|l|}
\hline $\begin{array}{l}\text { Grade Meningioma } \\
\text { (WHO) }\end{array}$ & Frequency & Percentase \\
\hline Grade 1 & 34 & 85.0 \\
Grade 2 & 5 & 12.5 \\
Grade 3 & 1 & 2.5 \\
\hline
\end{tabular}

From the results, Table 1 showed WHO grade 1 meningioma was 34 patients (85\%), WHO grade 2 was 5 patients $(5.5 \%)$ and $\mathrm{WHO}$ grade 3 was 1 patient $(2.5 \%)$. 
Patient Characteristics

Table 2. Distribution of patient age according to malignancy rate of meningioma.

\begin{tabular}{|c|c|c|c|c|c|c|c|}
\hline \multirow{3}{*}{$\begin{array}{l}\text { Age } \\
30-<40\end{array}$} & \multicolumn{6}{|c|}{ Grade Meningioma (WHO) } & \multirow{3}{*}{$\begin{array}{l}\text { Total } \\
7\end{array}$} \\
\hline & \multicolumn{2}{|l|}{1} & \multicolumn{2}{|l|}{2} & \multicolumn{2}{|l|}{3} & \\
\hline & 6 & $(85.7 \%)$ & 1 & $(14.3 \%)$ & 0 & $(0.0 \%)$ & \\
\hline $40-<50$ & 17 & $(85.0 \%)$ & 3 & $(15.0 \%)$ & 0 & $(0.0 \%)$ & 20 \\
\hline $50-<60$ & 10 & $(90.9 \%)$ & 1 & $(9.1 \%)$ & 0 & $(0.0 \%)$ & 11 \\
\hline$>60$ & 1 & $(50.0 \%)$ & 0 & $(0.0 \%)$ & 1 & $(50.0 \%)$ & 2 \\
\hline Total & 34 & $(85.0 \%)$ & 5 & $(12.5 \%)$ & 1 & $(2.5 \%)$ & 40 \\
\hline
\end{tabular}

The patient's age has a mean of $47.05 \pm 7.21$ years. The youngest patient was 30 years old while the oldest was 65 . The highest prevalence was in the 40 to 49 -year-old group. Table 2 showed the age distribution of patients according to meningioma malignancy. From the study, it was found that at the age of 30-60 years old, the incidence of WHO grade 1 meningioma was more commonly obtained. While at the age of 60 years was a tendency of WHO grade 3 meningiomas.

Table 3. Sex distribution of patients according to meningioma malignancy level.

\begin{tabular}{|c|c|c|c|c|c|c|c|}
\hline \multirow{3}{*}{$\begin{array}{l}\text { Sex } \\
\text { Male }\end{array}$} & \multicolumn{6}{|c|}{ Grade Meningioma (WHO) } & \multirow{3}{*}{$\begin{array}{l}\text { Total } \\
7\end{array}$} \\
\hline & \multicolumn{2}{|l|}{1} & \multicolumn{2}{|l|}{2} & \multicolumn{2}{|l|}{3} & \\
\hline & 4 & $(57.1 \%)$ & 2 & $(28.6 \%)$ & 1 & $(14.3 \%)$ & \\
\hline Female & 30 & $(90.9 \%)$ & 3 & $(9.1 \%)$ & 0 & $(0.0 \%)$ & 33 \\
\hline Total & 34 & $(85.0 \%)$ & 5 & $(12.5 \%)$ & 1 & $(2.5 \%)$ & 40 \\
\hline
\end{tabular}

The sex of patients women were 33 patients $(82.5 \%)$ more than men $7(17.5 \%)$. It was also found that in female patients had a tendency to meningioma WHO grade 1, while grade 3 occurred in men

Overview of Meningioma Aggressiveness on Preoperative MRI Examination that Correlated with Anatomical Pathology Results

The data was taken when one of the observer/assessor express positive, hence the picture of aggressiveness meningioma considered as positive.

Table 4. Meningioma aggressiveness on preoperative MRI examination that correlated with anatomical pathology

\begin{tabular}{|c|c|c|c|c|c|c|}
\hline \multirow{2}{*}{ Correlation } & \multirow{2}{*}{\multicolumn{2}{|c|}{$\begin{array}{l}\text { Diagnostics } \\
\text { Grade } 1\end{array}$}} & \multicolumn{3}{|c|}{ Grade meningioma (WHO) } & \multirow{3}{*}{$\begin{array}{l}\text { Total } \\
\\
23 \\
(57.5 \%)\end{array}$} \\
\hline & & & Grade 2 & Grade 3 & & \\
\hline \multirow{2}{*}{$\begin{array}{l}\text { Correlation of intratumoral cystic changes } \\
\text { with meningioma aggressiveness level }\end{array}$} & \multirow{2}{*}{$\begin{array}{l}\text { Intratumoral } \\
\text { cyctic changes }\end{array}$} & - & $\begin{array}{l}21 \\
(61.8 \%)\end{array}$ & $\begin{array}{l}2 \\
(40.0 \%)\end{array}$ & $\begin{array}{l}0 \\
(0.0 \%)\end{array}$ & \\
\hline & & + & $\begin{array}{l}13 \\
(38.2 \%)\end{array}$ & $\begin{array}{l}3 \\
(60.2 \%)\end{array}$ & $\begin{array}{l}1 \\
(100 \%)\end{array}$ & $\begin{array}{l}17 \\
(42.5 \%)\end{array}$ \\
\hline
\end{tabular}


Cont... Table 4. Meningioma aggressiveness on preoperative MRI examination that correlated with anatomical pathology

\begin{tabular}{|c|c|c|c|c|c|c|}
\hline \multicolumn{3}{|l|}{ Total } & 34 & 5 & 1 & $\begin{array}{l}40 \\
(100 \%)\end{array}$ \\
\hline \multirow{2}{*}{$\begin{array}{l}\text { Correlation of hyperostosis with } \\
\text { aggressiveness of meningioma }\end{array}$} & \multirow{2}{*}{ hyperostosis } & - & $\begin{array}{l}28 \\
(82.4 \%)\end{array}$ & $\begin{array}{l}2 \\
(40.0 \%)\end{array}$ & $\begin{array}{l}1 \\
(100 \%)\end{array}$ & $\begin{array}{l}31 \\
(77.5 \%)\end{array}$ \\
\hline & & + & $\begin{array}{l}6 \\
(17.6 \%)\end{array}$ & $\begin{array}{l}3 \\
(60.0 \%)\end{array}$ & $\begin{array}{l}0 \\
(0.0 \%)\end{array}$ & $\begin{array}{l}9 \\
(22.5 \%)\end{array}$ \\
\hline \multicolumn{3}{|l|}{ Total } & 31 & 5 & 1 & $\begin{array}{l}40 \\
(100 \%)\end{array}$ \\
\hline \multirow{2}{*}{$\begin{array}{l}\text { Correlation of bone destruction with } \\
\text { aggressiveness of meningioma }\end{array}$} & \multirow{2}{*}{$\begin{array}{l}\text { Bone } \\
\text { Destruction }\end{array}$} & - & $\begin{array}{l}33 \\
(97.1 \%) \\
\end{array}$ & $\begin{array}{l}3 \\
(60.0 \%) \\
\end{array}$ & $\begin{array}{l}0 \\
(0.0 \%) \\
\end{array}$ & $\begin{array}{l}36 \\
(90 . \%) \\
\end{array}$ \\
\hline & & + & $\begin{array}{l}1 \\
(2.9 \%) \\
\end{array}$ & $\begin{array}{l}2 \\
(40.0 \%) \\
\end{array}$ & $\begin{array}{l}1 \\
(100 \%)\end{array}$ & $\begin{array}{l}4 \\
(10 \%) \\
\end{array}$ \\
\hline \multicolumn{3}{|l|}{ Total } & 34 & 5 & 1 & $\begin{array}{l}40 \\
(100 \%)\end{array}$ \\
\hline \multirow{2}{*}{$\begin{array}{l}\text { Correlation of extracranial tumor extension } \\
\text { with aggressiveness of meningioma }\end{array}$} & \multirow{2}{*}{$\begin{array}{l}\text { Extracranial } \\
\text { tumor extension }\end{array}$} & - & $\begin{array}{l}30 \\
(88.2 \%)\end{array}$ & $\begin{array}{l}5 \\
(100 \%)\end{array}$ & $\begin{array}{l}1 \\
(100 \%)\end{array}$ & $\begin{array}{l}36 \\
(90 \%)\end{array}$ \\
\hline & & + & $\begin{array}{l}4 \\
(11.8 \%)\end{array}$ & $\begin{array}{l}0 \\
(0.0 \%) \\
\end{array}$ & $\begin{array}{l}0 \\
(0.0 \%) \\
\end{array}$ & $\begin{array}{l}4 \\
(10 \%)\end{array}$ \\
\hline \multicolumn{3}{|l|}{ Total } & 34 & 5 & 1 & $\begin{array}{l}40 \\
(100 \%)\end{array}$ \\
\hline \multirow{2}{*}{$\begin{array}{l}\text { Correlation of vascular encasement with level } \\
\text { of aggressiveness meningioma }\end{array}$} & \multirow{2}{*}{$\begin{array}{l}\text { Vascular } \\
\text { encasement }\end{array}$} & - & $\begin{array}{l}23 \\
(67.6 \%)\end{array}$ & $\begin{array}{l}5 \\
(100 \%)\end{array}$ & $\begin{array}{l}1 \\
(100 \%)\end{array}$ & $\begin{array}{l}29 \\
(72.5 \%)\end{array}$ \\
\hline & & + & $\begin{array}{l}11 \\
(32.4 \%)\end{array}$ & $\begin{array}{l}0 \\
(0.0 \%)\end{array}$ & $\begin{array}{l}0 \\
(0.0 \%)\end{array}$ & $\begin{array}{l}11 \\
(27.5 \%) \\
\end{array}$ \\
\hline \multicolumn{3}{|l|}{ Total } & 34 & 5 & 1 & $\begin{array}{l}40 \\
(100 \%)\end{array}$ \\
\hline \multirow{2}{*}{$\begin{array}{l}\text { Correlation of peritumoral cerebral edema } \\
\text { with aggressiveness of meningioma }\end{array}$} & \multirow{2}{*}{$\begin{array}{l}\text { Peritumoral } \\
\text { cerebral edema }\end{array}$} & - & $\begin{array}{l}9 \\
(26.5 \%) \\
\end{array}$ & $\begin{array}{l}1 \\
(20.0 \%)\end{array}$ & $\begin{array}{l}0 \\
(0.0 \%) \\
\end{array}$ & $\begin{array}{l}10 \\
(25 \%) \\
\end{array}$ \\
\hline & & + & $\begin{array}{l}25 \\
(73.5 \%)\end{array}$ & $\begin{array}{l}4 \\
(80.0 \%)\end{array}$ & $\begin{array}{l}1 \\
(100 \%)\end{array}$ & $\begin{array}{l}30 \\
(75 \%)\end{array}$ \\
\hline \multicolumn{3}{|l|}{ Total } & 34 & 5 & 1 & $\begin{array}{l}40 \\
(100 \%)\end{array}$ \\
\hline
\end{tabular}

Based on Table 4, there was a weak correlation between the presence of intratumoral cysts with meningioma malignancy $(\mathrm{C}=0.230)$. A weak correlation between the presence of hyperostosis with meningioma malignancy $(\mathrm{C}$ $=0.327)$. Strong relationship between the existence of bone destruction with meningioma malignancy $(\mathrm{C}=0.533)$. There was a very weak correlation between extension of extracranial tumor and malignancy rate of meningioma (C $=0.139)$. Weak relationship between the vascular encasement with malignancy rates meningioma $(\mathrm{C}=0.327)$. There was a very weak correlation between peritumoral brain edema with malignancy rate meningioma $(\mathrm{C}=0.104)$.

\section{Total Aggressiveness Score}

Table 5. Total aggressive image score of meningioma with malignancy level

\begin{tabular}{|l|l|l|l|l|l|}
\hline \multirow{2}{*}{$\begin{array}{l}\text { Grade Meningioma } \\
\text { (WHO) }\end{array}$} & \multirow{2}{*}{$\mathbf{n}$} & \multicolumn{2}{|l|}{ Aggressive score } & \multirow{2}{*}{ rs } \\
\cline { 3 - 6 } & & Median & Minimum & Maximum & \\
\hline Grade 1 & 34 & 2 & 0 & 5 & 0.130 \\
\hline Grade 2 & 5 & 1 & 1 & 3 & \\
\hline Grade 3 & 1 & 3 & 3 & 3 & \\
\hline
\end{tabular}


Table 5 showed that the results were a very weak correlation between the image of aggressiveness meningioma with malignancy rate meningioma $(\mathrm{rs}=$ 0.130). In meningioma WHO grade 1 was $0-5$ features (average 2 features) description of aggressiveness meningioma, WHO grade 2 was 1-3 features (average 1 feature) and WHO grade 3 was 3 features.

\section{Discussion}

Forty-patients diagnosed intracranial meningioma that performed surgery and examination of head MRI pre-operative and Anatomy Pathology examination. The patients have a mean of $47.05 \pm 7.21$ years. The youngest patient was 30 years old and the oldest was 65 years old. The highest prevalence in the age group 40-49 years was 20 patients $(50 \%)$, whereas in the age group 30-39 years was 7 patients (17.5\%), age group 5059 years was 11 patients $(27.5 \%)$ and age group over 60 -year-old was 2 people $(0.05 \%)$. In this study obtained female patients was 33 patients $(82.5 \%)$ more than men by 7 patients $(17.5 \%)$.

Meningiomas were categorized by WHO classification as benign (grade I), atypical (grade II), and anaplastic (grade III), $80 \%, 15-20 \%$, and $1-3 \%$ of all meningiomas 5,17 . From this research, there was 34 men $(85 \%)$ of WHO grade 1 meningioma, WHO grade 2 was $5(12.5 \%)$ and WHO grade 3 was $1(2.5 \%)$. Based on age obtained there were; at age $30-59$ years was 33 patients with WHO grade 1 intracranial meningioma and 5 patients with WHO grade 2 intracranial meningioma, also in the age group over 60 years old was 1 person with WHO grade 1 and 1 men intracranial meningioma with WHO grade 3 intracranial meningiomas.

Meningiomas are generally more common in women, with the dominance of 2-3 to 1 , but this trend is reduced in atypical and anaplastic meningiomas in children and radiation-induced meningioma ${ }^{17}$. Based on sex, women were more likely to suffer from WHO grade 1 intracranial meningioma by 30 patients $(90.9 \%)$ and $3(9.1 \%)$ with WHO grade 2 meningiomas. In men, $4(57.1 \%)$ patients were WHO grade 1, 2 (28.6\%) intracranial meningioma with WHO grade 2 while 1 men $(14.3 \%)$ intracranial meningioma with WHO grade 3 intracranial meningiomas. In this study, there was 1 men's meningioma of WHO grade 3 intrauterine with male sex and in the age group over 60 years old.

A retrospective study of 75 patients undergoing intracranial meningioma resection was performed to determine the correlation between aggressive imaging features and histopathologic classes in meningioma ${ }^{11}$. Six aggressive imaging features were evaluated: intratumoral cystic changes, adjacent cranial hyperostosis, bone destruction, extracranial tumor extension through skull base foramina, vascular encasement and peritumoral cerebral edema. Fifty-nine tumors were classified as benign, according to WHO classification, and 16 as atypical/malignant. Only intratumoral cystic changes and extracranial tumor extension through the skull base foramina are more common in atypical/malignant ${ }^{11}$. From the analysis, there was a strong correlation between bone destruction and meningioma malignancy $(\mathrm{C}=$ 0.533 ). While on other features have a weak correlation between the picture of aggressiveness meningioma with meningioma malignancy levels, cystic intratumoral changes $(C=0.230)$, hyperostosis $(C=0.327)$ and vascular encasement $(C=0.250)$. And there is a very weak association between the aggressive picture of meningioma and meningioma malignancy, extension of extracranial tumor $(\mathrm{C}=0.139)$ and peritumoral cerebral edema $(C=0.104)$.

The presence of an overview of intratumoral cystic changes was in 13 patients from 34 individuals $(38.2 \%)$ with WHO meningioma grade 1,3 patients from $5(60 \%)$ with WHO grade 2 meningiomas and 1 patient from $1(100 \%)$ with WHO meningioma grade 3 . From the results, there was a weak correlation between the existence of intratumoral cystic changes with meningioma malignancy.

The presence of hyperostotic features was in 6 of 34 patients $(17.6 \%)$ with WHO meningioma grade 1,3 patients of $5(60 \%)$ with WHO grade 2 meningioma and 0 patients of $1(0 \%)$ with WHO grade 3 meningiomas. The results, there was a weak correlation between the presence of hyperostosis with meningioma malignancy.

Bone destruction was present in 1 out of 34 patients $(2.9 \%)$ with WHO meningioma grade 1,2 of 5 patients (40\%) with WHO grade 2 meningiomas and 1 of 1 patients $(100 \%)$ with WHO grade meningioma 3. From the results, there was a strong correlation between the existence of bone destruction with meningioma malignancy. Extracranial tumor extension features were present in 4 of 34 patients $(11.8 \%)$ with WHO meningioma grade 1,0 of 5 patients $(0 \%)$ with WHO grade 2 meningiomas and 0 of 1 patients $(0 \%)$ with WHO meningioma grade 3 . From the results, that there was a very weak correlation between the extension of the 
extracranial tumor with malignancy rate meningioma.

Vascular encasement was present in 11 of 34 patients (32.4\%) with WHO grade meningioma 1, 0 of 5 patients $(0 \%)$ with WHO grade 2 meningiomas and none of 1 patients $(0 \%)$ with WHO grade meningioma 3 . From the results, there was a weak correlation between the vascular encasement with the malignancy rate of meningioma $(\mathrm{C}=0.327)$. Peritumoral brain edema was present in 25 of 34 patients $(73.5 \%)$ with WHO meningioma grade 1,4 of 5 patients $(80 \%)$ with WHO grade 2 meningiomas and 1 of 1 patients (100\%) with WHO meningioma grade 3 . From the results, there was a very weak correlation between peritumoral brain edema with malignancy rate meningioma $(C=0.104)$. From the total score of aggressive images of meningioma was a very weak correlation between the picture of aggressiveness meningioma with meningioma malignancy ( $\mathrm{rs}=0.130)$. Meningioma WHO grade 1 has $0-5$ features (average 2 features) meningioma aggressiveness picture, WHO grade 2 meningioma has 1-3 features (average 1 feature) description of aggressiveness meningioma, and meningioma WHO grade 3 has 3 features aggressiveness picture meningioma.

\section{Conclusion}

There was a strong correlation between bone destruction and malignancy rates in meningioma. The presence of a weak association of the aggressive features of meningioma was intratumoral cystic changes, hyperostosis, and vascular encasement with malignant levels in meningioma. The presence of a very weak correlation from the image of aggressive meningioma extension of extracranial tumor and peritumoral brain edema with malignancy levels in meningioma. From the total score of aggressive images of meningioma, there was a very weak correlation between the picture of aggressiveness meningioma with meningioma malignancy.

Ethical Clearance: This study protocol was approved by ethical clearance Dr.Soetomo Surabaya, Indonesia teaching hospital research.

Conflict of Interest: The author reports no conflict of interest of this work.

Source of Funding: This study is done with individual funding.

\section{References}

1. Shibuya M. Pathology and molecular genetics of meningioma: recent advances. Neurol Med Chir (Tokyo). 2014:ra-2014.

2. Kane AJ, Sughrue ME, Rutkowski MJ, et al. Anatomic location is a risk factor for atypical and malignant meningiomas. Cancer. 2011;117(6):1272-1278.

3. Ardern-Holmes S, Fisher G, North K. Neurofibromatosis Type 2: Presentation, Major Complications, and Management, with a Focus on the Pediatric Age Group. J Child Neurol. 2017;32(1):9-22. doi:10.1177/0883073816666736

4. Maxwell M, Shih SD, Galanopoulos T, HedleyWhyte ET, Cosgrove GR. Familial meningioma: analysis of expression of neurofibromatosis 2 protein merlin: report of two cases. J Neurosurg. 1998;88(3):562-569.

5. Riemenschneider MJ, Perry A, Reifenberger G. Histological classification and molecular genetics of meningiomas. Lancet Neurol. 2006;5(12):10451054

6. Wiemels J, Wrensch M, Claus EB. Epidemiology and etiology of meningioma. $J$ Neurooncol. 2010;99(3):307-314.

7. Lee JH. Meningiomas: Diagnosis, Treatment, and Outcome. Springer Science \& Business Media; 2008.

8. Levačić D, Nochlin D, Steineke T, Landolfi JC. Management of malignant meningiomas. Meningiomas Manag Surg. 2012:1.

9. Louis DN, Ohgaki H, Wiestler OD, et al. The 2007 WHO classification of tumours of the central nervous system. Acta Neuropathol. 2007;114(2):97109.

10. Yousem DM, Grossman RI. Neuroradiology: The Requisites. Elsevier Health Sciences; 2010.

11. Hsu C-C, Pai C-Y, Kao H-W, Hsueh C-J, Hsu W-L, Lo C-P. Do aggressive imaging features correlate with advanced histopathological grade in meningiomas? J Clin Neurosci. 2010;17(5):584587.

12. Choy W, Kim W, Nagasawa D, et al. The molecular genetics and tumor pathogenesis of meningiomas and the future directions of meningioma treatments. Neurosurg Focus. 2011;30(5):E6. 
13. Palma L, Celli P, Franco C, Cervoni L, Cantore G. Long-term prognosis for atypical and malignant meningiomas: a study of 71 surgical cases. $J$ Neurosurg. 1997;86(5):793-800.

14. Pasquier D, Bijmolt S, Veninga T, et al. Atypical and malignant meningioma: outcome and prognostic factors in 119 irradiated patients. A multicenter, retrospective study of the Rare Cancer Network. Int J Radiat Oncol Biol Phys. 2008;71(5):1388-1393.
15. Damayanti A, Werdiningsih I. Classification of tumor based on magnetic resonance (MR) brain images using wavelet energy feature and neurofuzzy model. J Phys Conf Ser. 2018;974(1). doi:10.1088/1742-6596/974/1/012027

16. Wen PY, Quant E, Drappatz J, Beroukhim R, Norden AD. Medical therapies for meningiomas. $J$ Neurooncol. 2010;99(3):365-378.

17. Marosi C, Hassler M, Roessler K, et al. Meningioma. Crit Rev Oncol Hematol. 2008;67(2):153-171. 